\title{
GenNòmos: um processo genérico para utilização do framework Nòmos
}

\author{
Hidelberg Albuquerque ${ }^{1}$, Carla Silva ${ }^{2}$, Danielle Rousy ${ }^{1}$ \\ ${ }^{1}$ Universidade Federal da Paraíba (UFPB) - João Pessoa/PB - Brasil \\ ${ }^{2}$ Universidade Federal de Pernambuco (UFPE) - Recife/PE- Brasil \\ filesberg@gmail.com, ctlls@cin.ufpe.br, danielle@ci.ufpb.br
}

\begin{abstract}
The Nomos Framework extends the $i^{*}$ framework to achieve legal compliance of information systems requirements. Government departments, from the content found in legal rules, enforce Legal Compliance. The notcompliance these requirements by software may cause legal and financial problems for the company and its solutions. On the other hand, the fact that Nomos relies on the framework $i^{*}$ can be an obstacle to its widespread adoption in industry. Therefore, this paper proposes to make Nomos independent of software requirements or business process modeling notation, instead of being exclusively applied to the $i^{*}$, as originally proposed.
\end{abstract}

Resumo. O Framework Nòmos estende o framework $i^{*}$ para alcançar a conformidade legal dos requisitos de sistemas de informação. A conformidade legal é uma exigência imposta por departamentos governamentais, a partir do conteúdo encontrado nas normas jurídicas. O não-cumprimento destas exigências por parte de um software pode acarretar transtornos legais e financeiros às empresas e suas soluções. Por outro lado, o fato do Nòmos ser dependente do $i^{*}$ pode ser uma barreira para a sua ampla adoção na indústria. Portanto, este trabalho propõe tornar o Nòmos independente de notação de modelagem de processos de negócio ou de requisitos de software, ao invés de ser aplicado exclusivamente no $i^{*}$, como proposto originalmente.

\section{Introdução}

Regulamentações são uma importante fonte de exigência às organizações, sobretudo quando estas exigências são feitas por departamentos governamentais. As regulamentações determinam o que é permitido, proibido ou requerido para um domínio de atuação e, do ponto de vista organizacional, elas descrevem práticas de negócio [Breaux and Powers 2009][Siena 2010]. Neste sentido, as empresas devem considerar tais exigências, interpretá-las e determinar "se" e "como" seus produtos de software e/ou suas práticas de negócio serão afetadas e, quando necessário, validar e modelar tais produtos/processos para que estes estejam sob a conformidade legal [Breaux and Powers 2009][Schleicher et al. 2010]. Estas adaptações podem exigir um alto custo financeiro para as empresas, sobretudo quando não-programadas. Contudo, o nãocumprimento da obrigatoriedade da conformidade legal pode levar a prejuízos maiores, tanto no âmbito legal, quanto no financeiro [Ciaghi et al. 2011][Ghanavati 2013].

Devido a sua importância, o caráter da conformidade legal deve ser analisado desde a fase de projeto de software e/ou desenho de processos [Ghanavati 2013] 
[Gordon and Breaux 2013]. Neste ínterim, é papel dos analistas de negócio e/ou engenheiros de requisitos investigarem o grau de influência e as condições de aplicabilidade das exigências legais no ciclo de vida de seus processos/sistemas e aplicar as devidas adaptações. A comprovação da conformidade legal deve ser feita através de modelos que expressem com clareza como as práticas de negócio observam a lei, mas em alto nível de abstração. Nesta ótica, uma representação visual clara de como acontece a interação "processos-leis" é um grande benefício [Ciaghi et al. 2011].

Neste sentido, pesquisas vêm sendo desenvolvidas com o objetivo de extrair e mapear requisitos legais, e entender como estes impactam nos requisitos das organizações. Entre outros exemplos, destacamos os trabalhos de Breaux and Powers (2009), Siena (2010), Gordon and Breaux (2013) e Ingolfo et al. (2013). Em particular, destacamos o framework Nòmos [Siena 2010], cujo processo de elicitação e modelagem de requisitos legais apresenta-se claro e sistemático o suficiente para ser aplicado em qualquer domínio de aplicação. Contudo, o Nòmos é uma extensão do i* [Yu 1997], e devido ao fato desta linguagem não ser muito popular na indústria (majoritariamente por causa da complexidade visual de seus modelos), a adoção do Nòmos na indústria pode ser prejudicada. Em virtude disto, pensamos ser necessário adaptar o Nòmos, deixandoo mais independente do $i^{*}$ e aplicável a qualquer linguagem de modelagem de requisitos ou de processos de negócio. Assim, praticantes de outras linguagens de modelagem poderiam adotar o Nòmos mais facilmente, no intuito de alcançar a conformidade legal de seus processos de negócio e/ou sistemas de software.

Este artigo está organizado como segue. A seção 2 apresenta as bases teóricas nas quais apoiamos esta pesquisa. A seção 3 descreve a proposta deste trabalho e sua aplicabilidade. A seção 4 apresenta uma análise de trabalhos relacionados. Finalmente, a seção 5 sintetiza nossa proposta e destaca questões a serem trabalhadas.

\section{O Framework Nòmos}

O framework Nòmos [Siena 2010] é uma linguagem de modelagem de requisitos legais fundamentada nos conceitos da Engenharia de Requisitos Orientada à Objetivos. Estendendo a linguagem $i^{*}$ [Yu 1997], Nòmos foca sua análise no ambiente organizacional onde sistema ou processo está inserido (considerando stakeholders e regulamentações), capturando seus relacionamentos sociais e intencionais, proporcionando assim um melhor entendimento do problema em estudo, das razões que envolvem as tomadas de decisão e a descrição de potenciais alternativas para satisfação dos requisitos. O framework provê uma metodologia para análise da conformidade legal, buscando nos requisitos dos stakeholders a realização das exigências legais, encontradas nas normas jurídicas. O resultado final é a geração de um modelo de requisitos que represente um conjunto de Requisitos Legais, resultado do refinamento e sincronização dos requisitos do negócio às leis, garantindo que as propriedades de cumprimento e conformidade legais sejam realizadas [Siena 2010] [Ingolfo et al 2013].

Para se fazer uma análise efetiva sobre o impacto legal nos requisitos de software ou processo de negócio, é preciso antes de tudo, ter conhecimento sobre a natureza jurídica. Os princípios legais utilizados por Nòmos são baseados em Hohfeld (1913), que enxerga as relações jurídicas como relacionamentos de dependência entre sujeitos legais. Tal abordagem remodela os conceitos reducionistas de direito e dever em 
oito tipos, correlacionados em pares. O entendimento apropriado de cada conceito legal exige que sua análise seja projetada sempre na direção de seu par, como explicitado:

- Claim-Duty: afirmar que "o sujeito J tem um dever para com o sujeito K", significa dizer que J é obrigado a executar uma ação A em favor de K. Por sua vez, K tem um direito em relação à $\mathrm{J}$, podendo reivindicar (claim) o cumprimento de sua obrigação.

- Privilege-NoClaim: privilégio é uma liberdade que o sujeito J possui de decidir pela execução de alguma ação A em favor do sujeito K. Correlativamente, o sujeito K não tem direito (ou o "não-direito", no-claim) de exigir a execução da ação A por J.

- Power-Liability: o conceito de poder está ligado à capacidade ou competência que o sujeito K possui sobre a vontade do sujeito J, forçando-o a executar uma ação A. Por estar subordinado nesta relação, o sujeito $\mathrm{J}$ tem a responsabilidade de executar A.

- Immunity-Disability: a partir do entendimento anterior, se o sujeito J conseguir provas de que é incapaz de cumprir a ação A, J é considerado imune e, portanto, desobrigado da ação. Por sua vez, diante da incapacidade de J, o sujeito K não pode exigir-lhe o cumprimento de A.

Nòmos utiliza o conceito legal de Proposição Normativa (do inglês Normative Proposition - NP), para identificação dos sujeitos legais, os tipos de direito e da especificação do conteúdo legal. Visualmente, Nòmos representa os tipos de relações legais conforme demonstrado na Figura 1(a). A leitura desta representação é feita sempre na direção do sujeito a quem se obriga o cumprimento legal. A Figura 1(b) apresenta um modelo parcial de dependências legais e relações de dominância para o domínio de e-Commerce.

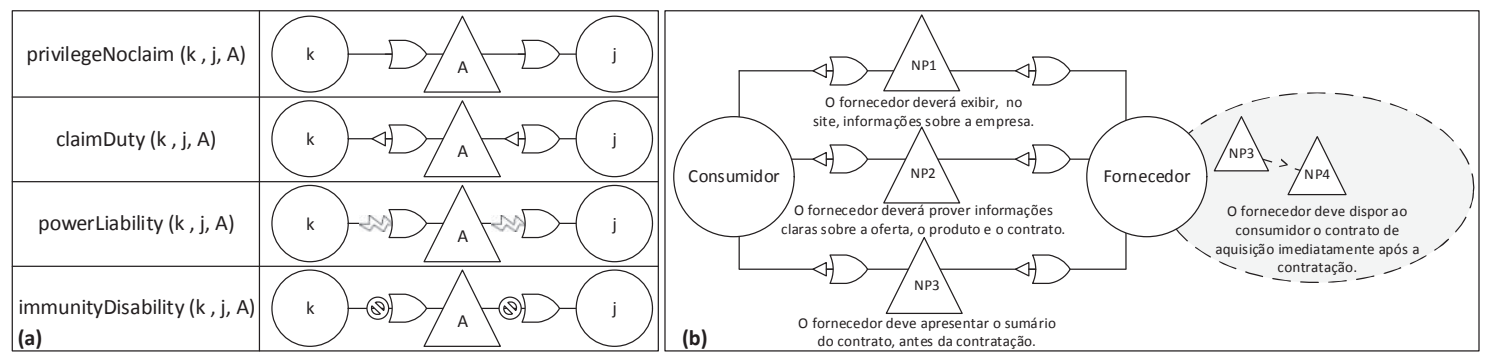

Figura 1. Representação Legal em Nòmos

O método proposto por Nòmos é dividido em três fases lógicas: (i) Processo de Elicitação de Requisitos, (ii) Processo de Modelagem e (iii) Processo de Verificação de Conformidade Legal, compondo um processo sistemático claro.

A primeira fase do processo (Elicitação de Requisitos) é subdividida em duas etapas: (i) Elicitação dos Requisitos dos Stakeholders, e (ii) Levantamento de Leis. Primeiramente, é feito o levantamento dos requisitos dos stakeholders, podendo ser utilizadas quaisquer técnicas de elicitação. A segunda etapa envolve a busca por legislações que estejam relacionadas ao campo de atuação da organização e/ou ao domínio da aplicação. A ordem de execução destas etapas também pode ser invertida, ou ainda feitas em paralelo (se executadas por profissionais distintos), ficando esta decisão à critério dos analistas. 
$\mathrm{Na}$ segunda fase do processo (Modelagem), os requisitos e as leis são analisadas do ponto de vista da conformidade legal, utilizando as seguintes etapas de modelagem: (i) Personificação de Sujeitos Legais, (ii) Identificação de Alternativas Legais, (iii) Busca por Realizações, (iv) Operacionalização de Objetivos de Conformidade e (v) Identificação de Artefatos de Prova. A primeira etapa busca relacionar os atores dos requisitos e os sujeitos legais. Quando identificada essa ligação, o ator do domínio passa a ser considerado um Sujeito Legal e personifica (embodies) o sujeito legal, seus direitos e deveres. A segunda etapa procura identificar cenários alternativos de prescrições legais e as relações de dominância entre estes cenários. Estas relações de dominância são descritas na expressão "NPy > NPx". Nesta relação, o cumprimento de um cenário ou lei não confronta a outra, e a execução de quaisquer umas das alternativas torna válida a relação de conformidade. A terceira etapa detêm-se na análise dos elementos comportamentais dos atores em face às leis selecionadas. Para que o ator possa alcançar a conformidade legal, ele deve atender dois critérios [Ingolfo et al 2013]: Prova de Cumprimento (para cada NP selecionada deve existir minimamente um elemento que a realize, ou que participe de uma relação de dominância com NP realizada) e a Prova de Conformidade (não deve haver nenhum elemento em situação irregular à NP, seja esta de violação ou de afetação). Desta forma, é preciso modificar, refinar ou excluir os requisitos conflitantes, ou adicionar requisitos faltosos, para que se estabeleça a conformidade esperada. A quarta etapa do processo se dá pelo refinamento dos requisitos legais (expressos no modelo de objetivos do i*) em identificação e execução de tarefas que, na prática, executam os requisitos. A quinta etapa procura localizar e/ou inserir artefatos/recursos que possam provar, em tempo de execução, que o processo ou software está sob conformidade legal.

A última fase do processo (Verificação), prevê a verificação do conjunto de requisitos refinados, das leis relacionadas e dos documentos gerados nas etapas anteriores, e se estes estão em conformidade legal e em conformidade com o modelo. Caso sejam encontradas inconsistências, a modelagem deverá ser refeita, correndo-se o risco de que todo o processo de negócio seja revisado. Quando não houverem mais modificações a serem executadas, o processo é finalizado.

Para ilustrar o Nòmos, especificamos os requisitos de um software no domínio de Comércio Eletrônico. A decisão por este domínio se deu a partir da constatação: (i) do aumento deste tipo de transações na América Latina e no Brasil [Almeida 2012] [Almeida 2013], (ii) crescimento de reclamações relacionadas à transgressões de direitos dos consumidores on-line brasileiros [Crespo 2012], e (iii) recente promulgação da Lei Brasileira que rege o comércio eletrônico no país [BRASIL 2013]. Devido ao escopo deste documento, o cenário de requisitos e leis foi reduzido, e apenas uma parte do sistema analisado é apresentada.

A Figura 2 mostra uma representação parcial do modelo de requisitos legais gerado em Nòmos, para o domínio do e-Commerce: (i) os fragmentos de lei foram extraídos de [BRASIL 2013], e regulamentam obrigações que os sites de compra têm que cumprir em benefício dos clientes; (ii) as NPs são representadas tanto externa quanto internamente à fronteira dos atores, para expressar a dependência legal entre os atores (representação externa) e demonstrar como o ator cumprirá ou realizará a exigência jurídica (representação interna). A geração do modelo apresentado na Figura 2 
congrega os modelos de representação de requisitos e dependências legais apresentados anteriormente, demonstrando o processo de modelagem e ratificando sua consistência.

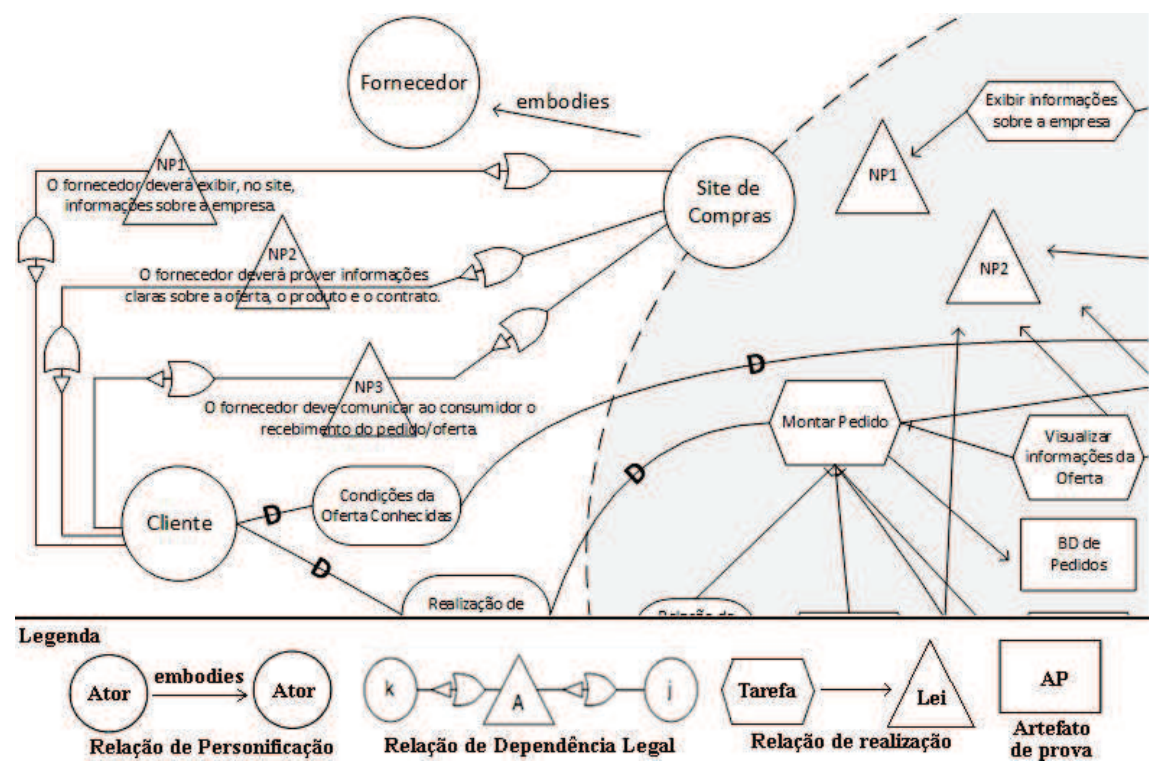

Figura 2. Modelo parcial do documento final de requisitos legais em Nòmos

\section{O GenNòmos: O Nòmos Genérico}

Reconhecendo a eficácia do Nòmos, este trabalho propõe adaptar este processo, no intuito de torná-lo flexível e adaptável à outras notações de modelagem diferentes do i*

No intuito de tornar o Nòmos genérico, sem contudo perder a sua essência, nossa proposta elegeu partes do seu processo que devem manter-se iguais, outras que devem se tornar independentes de linguagem de modelagem, e outras que podem ser adaptadas à linguagem de modelagem escolhida. De maneira geral, a seguir são descriminadas as etapas do processo original, com as diretrizes propostas para sua execução, seguidas das adaptações sugeridas:

- [Fase 1: Elicitação de Requisitos / Etapa 1: Requisitos dos Stakeholders]: a fase de elicitação de requisitos praticamente não é modificada, à exceção de que os analistas são livres para decidir quais técnicas/modelos serão utilizados. Contudo, alertamos para o fato de que, para evitar esforço desnecessário relacionados à conversão de modelos, e para dar maturidade ao processo, uma vez escolhida a linguagem de modelagem de requisitos, esta deverá ser seguida até o final.

- [Fase 1: Elicitação de Requisitos / Etapa 2: Busca e Modelagem de Conteúdo Legal]: uma vez que a análise legal proposta por Nòmos demonstrou-se consistente, esta etapa deve permanecer imutável, inclusive na representação gráfica das leis e suas relações de dependência entre os sujeitos legais (vide Figura 1). Devido à complexidade do conteúdo e dos textos legais, ratificamos a importância de que esta etapa seja feita por especialistas do ramo do Direito. Além disso, propomos a junção da etapa Identificação de Alternativas Legais do processo original à esta etapa, para que a execução da modelagem do conteúdo legal (utilizando o formato de NPs) e a identificação das relações de dominância entre elas sejam feitas pelos profissionais qualificados. Por fim, apresentamos as seguintes diretrizes que possam auxiliar na 
seleção do conteúdo legal: (i) entendimento do domínio da aplicação ou processo de negócio, e busca por legislações relacionadas nas diferentes jurisdições de atuação (se for o caso); (ii) identificação dos sujeitos legais no textos legais selecionados, especificando direitos e deveres, a partir da taxonomia hohfeldiana; (iii) seleção de padrões comportamentais específicos, explícitos ou implícitos na lei, tanto para o processo de negócio de maneira geral, quanto às ações esperadas pelos sujeitos; (iv) pesquisa por jurisprudência relacionada, principalmente se o produto/processo for utilizado em jurisdições diferentes; (v) definição e mapeamento das NPs; (vi) procura por cenários alternativos de prescrição e estabelecimento de relações de dominância. De posse destes dados, deve-se fazer a análise pela tomada de decisão correspondente ao tipo de conformidade legal desejada, e aos riscos de seu cumprimento, total ou parcial. Uma vez que uma NP pode conter a junção de fragmentos de leis correlacionadas, não-necessariamente presentes num mesmo documento, propomos a documentação das NP's utilizando o Modelo NPx (vide Tabela 1), derivado da proposta de (Siena 2010):

Tabela 1. Modelo NPx: elementos da Proposição Normativa

\begin{tabular}{|r|l|}
\hline \multicolumn{2}{|c|}{$N P x=\{$ [actor], [counterParty], [rightType], [action], [legalBasis], [jurisdiction] $\}$} \\
\hline NPx & identificação da proposição normativa \\
\hline actor & sujeito passivo da ação (quem se obriga o cumprimento legal) \\
\hline counterParty & sujeito ativo da ação (quem a lei beneficia e pode reinvidicar o direito) \\
\hline rightType & declaração do tipo de direito especificado, baseado em Hohfeld (1913) \\
\hline action & a ação/comportamento que deve ser executado no processo/produto \\
\hline legalBasis & identificação do fundamento jurídico (rastreabilidade) \\
\hline jurisdiction & jurisdição onde as bases legais são aplicáveis \\
\hline
\end{tabular}

- [Fase 2: Processo de Modelagem / Etapa 1: Personificação de Sujeitos Legais]: esta identificação poderá ser feita explicitamente, pela correlação nominal, ou implicitamente, pela análise de comportamentos comuns entre os sujeitos legais e os atores do processo/produto. Enfatizamos a necessidade de uma representação textual ou visual (ou ambas), adaptável ao modelo que será utilizado, para facilitar o entendimento visual da personificação, principalmente para leitura de usuários não acostumados ao modelo escolhido. A título de exemplo, a Figura 2 demonstra este relacionamento entre atores no modelo $i^{*}$.

- [Fase 2: Processo de Modelagem / Etapa 2: Busca por Realizações]: para cada NP anteriormente selecionada, deverão ser localizados nos atores legais do processo os elementos comportamentais que realizam ou levam à NP ao seu cumprimento pleno. Por via de regra, assumimos integralmente as diretrizes propostas no Nòmos e enfatizadas por Ingolfo et al (2013), para as Provas de Cumprimento e Conformidade: (i) não poderá haver nenhum comportamento que seja contrário à ação de nenhuma NP; (ii) não poderão haver comportamentos que, mesmo não estando em discordância, estejam em dissonância com alguma NP, e vice-versa; (iii) todas as NP's deverão ser realizadas. Por fim, ressaltamos que os analistas são livres para utilizarem quaisquer técnicas de análise e negociação de requisitos com seus 
clientes, objetivando o consenso e o refinamento destes frente aos requisitos legais. Destacamos ainda, a necessidade de uma representação gráfica clara das relações de realizações, no modelo de requisitos escolhido.

- [Fase 2: Processo de Modelagem / Etapa 3: Operacionalização de Realizações]: originalmente, as relações de realização em Nòmos são feitas pela ligação entre o modelo de objetivos (goals) da linguagem i* (que expressam comportamentos de alto nível) às NPs selecionadas. Estes objetivos não expressam, de fato, como os comportamentos serão alcançados, o que será detalhado pelo refinamento destes objetivos em tarefas (tasks). Todavia, em alguns modelos de requisitos, a identificação comportamental é feita diretamente no modelo de tarefas, como é o caso do diagrama de processo de negócio do BPMN [OMG, 2010] e do diagrama de caso de uso [Jacobson et al., 1992]. Portanto, na nossa proposta, pensamos que esta etapa possa ser omitida ou readaptada, a partir da análise do modelo escolhido.

- [Fase 2: Processo de Modelagem / Etapa 4: Identificação de Artefatos de Prova]: quando necessário, os documentos gerados durante as etapas de especificação dos requisitos, podem ser utilizados para provar que o processo sob análise foi projetado observando a regulamentação relacionada. Esta condição de auditabilidade é verificada pela pessoa do Magistrado, ou por aqueles que receberam esta responsabilidade [Siena 2010]. Contudo, geralmente estas autoridades não possuem este conhecimento técnico e, para estes, a comprovação da conformidade legal deve também fazer parte da solução desenvolvida, sendo capazes de demonstrar a observância legal da solução em tempo de execução (sobretudo nas soluções de software). Caso seja necessário a utilização destes tipos de recursos, os analistas de requisitos devem fazer as inserções nos modelos utilizados, certificando-se de destacá-los visualmente como "artefatos de prova", dos demais recursos utilizados.

- [Fase 3: Processo de Verificação]: propomos que sejam mantidas as mesmas regras utilizadas no Nòmos original: validação de todos os artefatos produzidos, para que estes estejam de acordo com o modelo utilizado, e sob a Conformidade Legal.

\subsection{Exemplo de aplicação}

Para demonstrar a aplicabilidade do GenNòmos, optamos por executá-la utilizando o domínio do e-Commerce (pelos motivos explicitados anteriormente), empregando nossa proposta em dois modelos específicos: BPMN e Diagramas de Casos de Uso.

O BPMN (do inglês, Business Process Model and Notation) é capaz de fornecer a compreensão das etapas e dos procedimentos internos de um processo em uma notação gráfica clara. Esta notação representa os processos de trabalho como atividades a serem executadas em um método ordenado de fluxos de ações, consumo e produção de recursos, e comunicação de dados. A Figura 3 apresenta um modelo parcial de um modelo de requisitos produzido para o domínio de e-Commerce, somente a parte do sistema. Um modelo da aplicação do Nòmos à BPMN está em Albuquerque et al (2014).

O Diagrama de Caso de Uso faz a representação visual de requisitos obtidos das descrições textuais do ponto de vista do usuário para as funcionalidades de um sistema, e tem por objetivo auxiliar a comunicação entre os profissionais de requisitos e os clientes [Jacobson et al. 1992]. Neste modelo, as exigências ou funcionalidade do 
sistema/processo pretendido são representadas por casos de uso e são associados e executados por atores. Atores são entidades que representam usuários (sejam estes pessoas ou outros sistemas) [OMG 2011]. A Figura 4 apresenta um diagrama de casos de uso parcial, produzido para o domínio de e-Commerce.

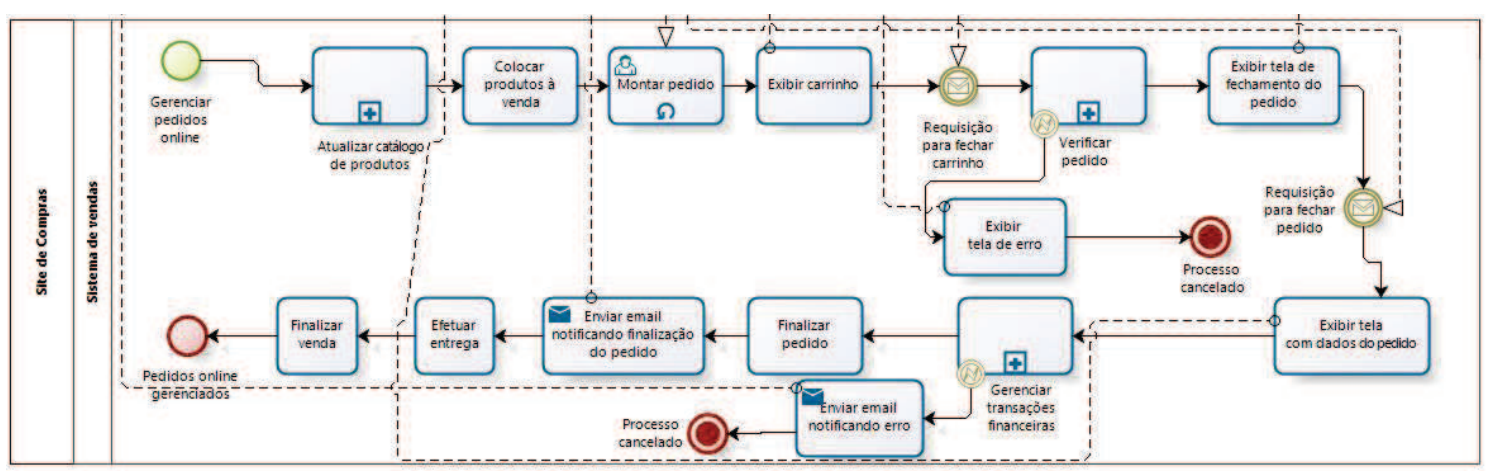

Figura 3. Modelo parcial de requisitos para e-Commerce, em BPMN

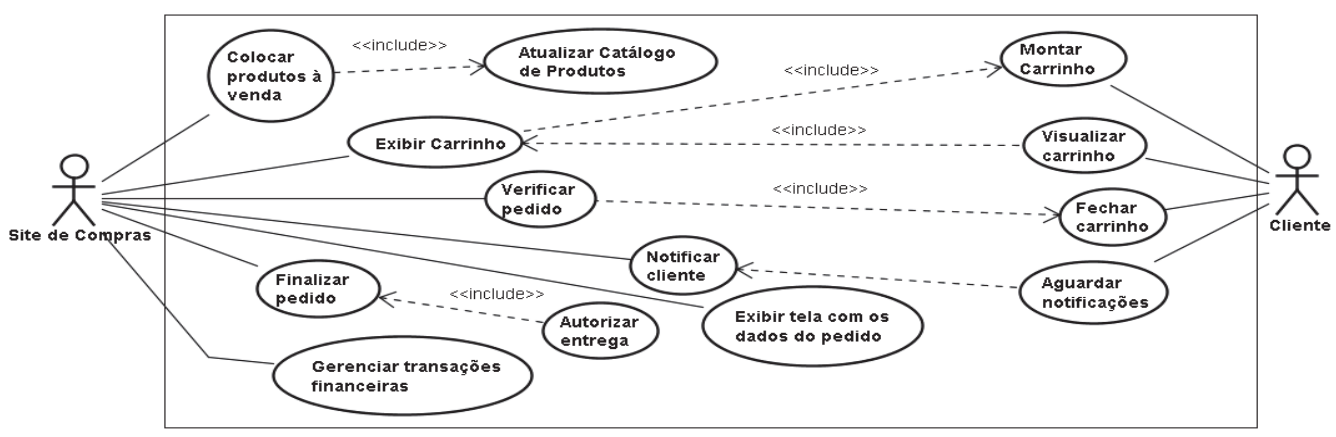

Figura 4. Modelo parcial de requisitos para e-Commerce, em Diagrama de Casos de Uso

A escolha destes modelos foi motivada devido (i) à sua popularidade tanto na indústria como na academia [OMG 2010][OMG 2011], (ii) por permitirem um entendimento do problema analisado num alto nível de abstração, e (iii) por estes modelos não terem sido projetados originalmente para a representação da análise legal. Salientamos ainda que, para não comprometer a popularidade e aplicabilidade de quaisquer modelos, as alterações sugeridas pretendem causar o mínimo de impacto nos modelos originais. Por fim, a aplicabilidade de nossa abordagem será demonstrada a seguir, com as devidas propostas para os modelos citados.

- [Fase 1: Elicitação de Requisitos / Etapa 1: Requisitos dos Stakeholders]: a especificação dos requisitos levantados para o desenvolvimento do software para o domínio do e-Commerce (somente a parte do sistema), são demonstrados na Figura 3 (em BPMN) e na Figura 4 (Diagrama de Casos de Uso).

- [Fase 1: Elicitação de Requisitos / Etapa 2: Busca e Modelagem de Conteúdo Legal]: a representação dos relacionamentos legais é demonstrada na Figura 1.

- [Fase 2: Processo de Modelagem / Etapa 1: Personificação de Sujeitos Legais]: propomos a representação visual destes relacionamentos de personificação em cada modelo utilizado. Assim, para a notação BPMN, adicionamos à descrição da piscina/raia relacionada ao ator que personifica o sujeito legal, uma pequena 
significação textual, simbolizando a relação (vide Figura 5(a)). Para o Diagrama de Caso de Uso, propomos o uso de generalização de Atores para realçar esta relação, como demonstrando na Figura 5(b).

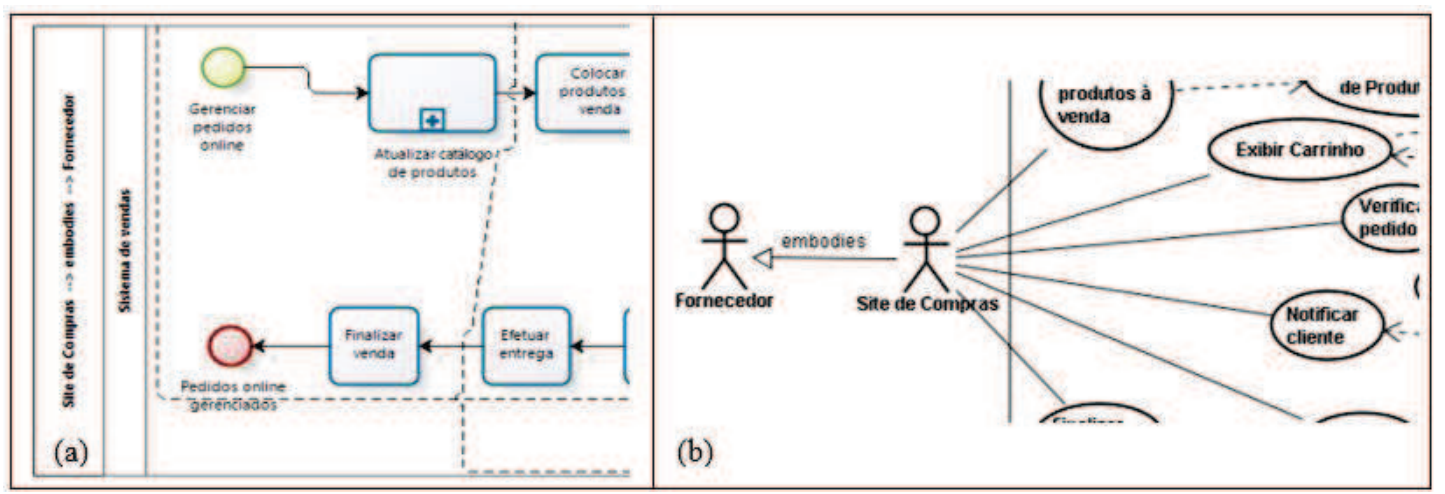

Figura 5. Relações de Personificação

- [Fase 2: Processo de Modelagem / Etapa 2: Busca por Realizações]: enfatizamos que os elementos que realizam às NPs devem ter destaque na representação visual. Assim, para BPMN, identificamos estes elementos utilizando o elemento grupo desta notação, rotulado com a NP realizada (vide Figura 6(a)). Caso seja necessário o refinamento de algum elemento, estes devem ser colocados dentro de um subprocesso, que deverá possuir a notação de realização. Para o Diagrama de Caso de Uso, propomos a adição de um estereótipo com a designação da NP realizada dentro do caso de uso correspondente (vide Figura 6(b)). De forma similar, caso seja necessário refinar algum elemento, estes devem ser agrupados em pacote, nomeado com a NP a ser realizada.

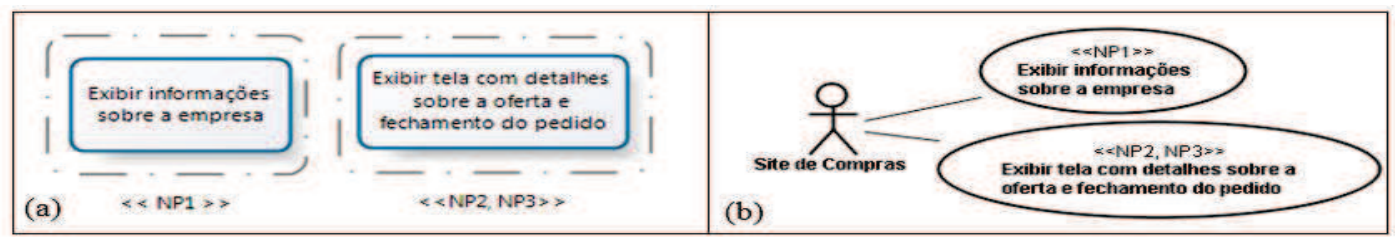

Figura 6. Relações de Realização

- [Fase 2: Processo de Modelagem / Etapa 3: Operacionalização de Realizações]: como tanto em BPMN como no Diagrama de Caso de Uso, as atividades/funcionalidades são expressas por elementos comportamentais (como tarefas, eventos, funções, etc.), em nossa abordagem esta etapa foi omitida.

- [Fase 2: Processo de Modelagem / Etapa 3: Identificação de Artefatos de Prova]: para demonstrar a observância legal em tempo de execução, em BPMN propomos a identificação e utilização dos elementos de dados rotulado com o texto $\langle<A P\rangle>$, (vide Figura 7(a)). No Diagrama de Caso de Uso, como não existem originalmente objetos de dados no modelo, propomos a utilização do elemento Anotação, adicionado de um estereótipo. Esta anotação deverá estar ligada ao caso de uso relacionada (vide Figura 7(b)).

- [Fase 3: Processo de Verificação]: como esta fase se detêm sobre a validação dos modelos, do processo, das leis e da documentação gerada, ela não foi alterada. 
(a)

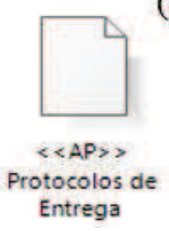

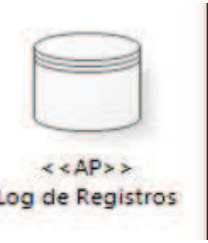

(b)

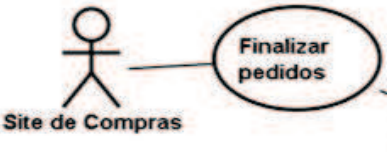

Site de Compras

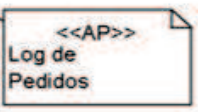

Figura 7. Identificando Artefatos de Prova

Por fim, ao final das etapas, deverão ser gerados os documentos que expressam como o software/processo cumpre com a Conformidade Legal exigida, seja utilizando a notação BPMN adaptada (Figura 8) ou o Diagrama de Caso de Uso adaptado (Figura 9).

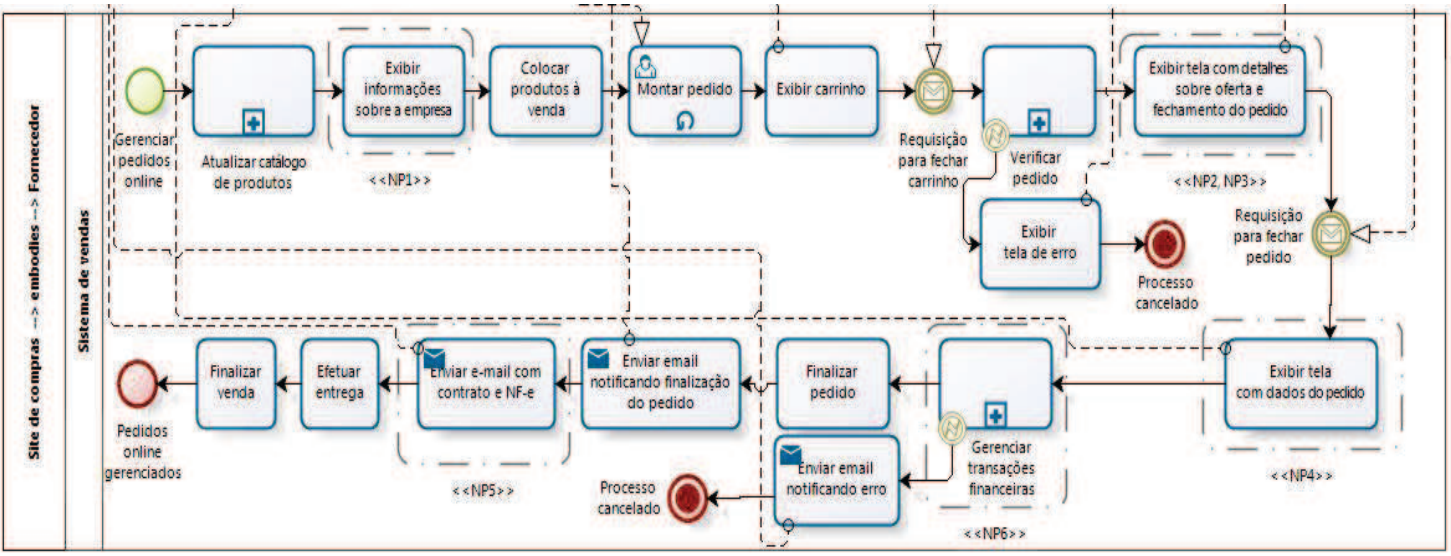

Figura 8. Modelo parcial de conformidade legal de requisitos para o domínio do e-Commerce, em BPMN.

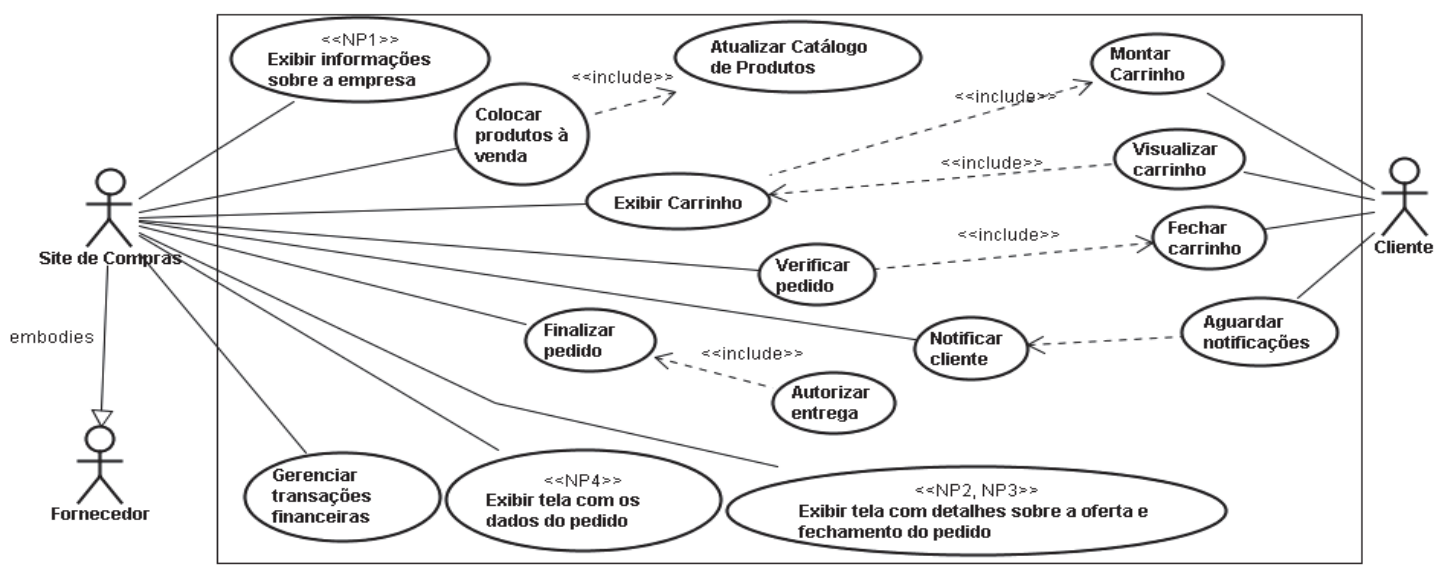

Figura 9. Modelo parcial de conformidade legal de requisitos para o domínio do e-Commerce, em Diagrama de Caso de Uso.

\section{Trabalhos relacionados}

Siena (2010) estende os conceitos organizacionais da linguagem i* [Yu 1997], apresentando o framework Nòmos como uma solução lógico-conceitual para se alcançar o caráter da conformidade legal de requisitos de software. Uma limitação ao trabalho reside no forte acoplamento aos modelos $i^{*}$, exigindo o conhecimento prévio desta linguagem que não é muito popular na indústria. Ingolfo et al. (2013) estende o 
framework Nòmos, no contexto da camada de argumentação, com uma proposta de suporte à tomada de decisão baseada em na análise de algoritmos e grafos orientados.

Breaux and Powers (2009) propõem um método para análise de requisitos legais, utilizando uma ferramenta de mapeamento de requisitos legais dentro dos textos legais, facilitando sua rastreabilidade. Depois de mapeados, os requisitos legais são convertidos em atividades no modelo BPMN, contendo o texto do requisito legal, a ação que deverá ser executada no sistema e uma anotação anexada à tarefa identificando a lei de origem. A limitação identificada neste trabalho baseia-se na marcação feita pela ferramenta proposta, que acontece empregando pesquisa por termos textuais específicos (como Obligation, Permission, etc.) nos textos legais. Neste caso, a adoção desta ferramenta em jurisdições de idiomas diferentes (ou até que utilizem sinônimos não contemplados na ferramenta) pode inviabilizar sua proposta, ou necessitar de extensão da ferramenta.

Ghavanati (2013) apresenta uma abordagem orientada a objetivos, baseada na linguagem URN (User Requirements Notation), para descrever e combinar a legalidade dos modelos organizacionais. Contudo, julgamos o Nòmos mais simples de ser usado e, por isso, o adotamos em nossa proposta.

\section{Conclusão e Trabalhos Futuros}

A linha de investigação apresentada neste trabalho está relacionada à necessidade de alcançar a conformidade legal em software e/ou processos de negócio. Dentre as abordagens existentes para tratar desta questão, o framework Nòmos [Siena 2010] destacou-se por apresentar um processo sistemático de identificação e refinamento dos requisitos dos stakeholders em direção à sua conformidade legal. Todavia, por ser fundamentado na linguagem $i^{*}$ [Yu 1997], o Nòmos exige o conhecimento prévio desta linguagem, o que pode comprometer a sua adoção na indústria.

Diante desta limitação, este trabalho propõe tornar o processo Nòmos independente de notação de modelagem de requisitos. Para ilustrar a proposta, foram utilizados o diagrama de processo de negócio do BPMN [OMG 2010] e o diagrama de casos de uso [Jacobson et al. 1992] da UML (OMG, 2011). Estes diagramas foram escolhidos por possuírem boa aceitação tanto na indústria como na academia, e por possibilitar uma comunicação de alto nível com os stakeholders. Pela popularidade destes diagramas, entendemos que o GenNòmos terá mais facilidade de ser adotado na indústria. Como contribuição secundária, temos a aplicação do Nòmos a especificação de um software de comércio eletrônico em conformidade com as leis brasileiras.

Para validar de forma mais efetiva a nossa proposta, esta abordagem deve ser aplicada à outros domínios distintos do Comércio Eletrônico, bem como a outras notações de modelagem de requisitos. Também é necessário avaliar o processo com relação à sua facilidade de uso, aplicabilidade à outros domínios, e uma avaliação qualitativa com equipes de desenvolvimento, que poderá apontar aspectos da nossa proposta que podem ser melhorados.

\section{Referências}

Albuquerque, H.O., Silva, C., Silva, D. R. D. (2014) "NòmosBPMN: Adaptando o Nòmos para a Modelagem de Processos de Negócio", In: CibSE 2014, XVII Congresso Ibero-Americano em Engenharia de Software, Pucón, Chile. 
Almeida, B. (2012) "Comércio Eletrônico dá um Salto de Quase 43\% na América Latina”, http://brasillink.usmediaconsulting.com/2012/05/comercio-eletronico-daum-salto-de-quase-43-por-cento-na-america-latina/.

Almeida, B. (2013) "O mercado de comércio eletrônico no Brasil e América Latina em 2013”, http://brasillink.usmediaconsulting.com/2013/02/o-mercado-de-comercioeletronico-na-latam-em-2013/.

BRASIL. (2013) "Decreto n. ${ }^{\circ}$ 7.962, de 15 de março de 2013. Regulamenta a Lei n. ${ }^{\circ}$ 8.078, de 11 de setembro de 1990, para dispor sob a contratação do comércio eletrônico", In: Diário Oficial da República Federativa do Brasil. Brasília, DF, n. 51, p. 01, 15 Março, Seção 1, Ed. Extra.

Breaux, T., Powers, P. (2009) "Early Studies in Acquiring Evidentiary, Reusable Business Process Models for Legal Compliance", In: 6th International Conference on Information Technology, New Generations, Amman, Jordan, p. 272-277.

Ciaghi, A., Weldemariam, K., Villafiorita, A. (2011) "Law Modeling with Ontological Support and BPMN: a Case Study", In: CYBERLAWS 2011, The 2nd International Conference on Technical and Legal Aspects of the e-Society, Guadeloupe, France.

Crespo, A. (2012) "E-commerce cresce em receita e em reclamação", http://www.dcomercio.com.br/index.php/economia/sub-menu-comercio/98549-ecommerce-cresce-em-receita-e-em-reclamacao/.

Ghanavati., S. (2013) "Legal-URN Framework for Legal Compliance of Business Processes", PhD Thesis. University of Ottawa, Canada.

Gordon, D., Breaux, T. (2013) "Assessing Regulatory Change through Legal Requirements Coverage Modeling”, In: 21st IEEE Intl. RE Conf., Rio de Janeiro, Brasil.

Hohfeld. W. (1913) "Some Fundamental Legal Conceptions as Applied in Judicial Reasoning”, In: Yale Law Journal 23.

Ingolfo, S., Siena, A., Mylopoulos, J., Susi, A., Perini, A. (2013) "Arguing regulatory compliance of software requirements", In: Data \& Knowledge Engineering.

Jacobson, I. Christerson, M., Jonsson P., Overgaard, G. (1992) “Object-Oriented Software Engineering: A Use-Case Driven Approach”, Addison-Wesley.

OMG (2010) "Business Process Modeling Notation Specification", http://www.bpmn.org, 2010.

OMG. (2011) "Unified Modeling Language (UML): Superstructure", http://www.uml.org/.

Schleicher, D., Leymann, F., Weidmann, M. (2010) "Compliance Scopes: Extending the BPMN 2.0 Meta Model to Specify Compliance Requirements", In: IEEE Intl. Conf. on Service-Oriented Computing and Applications (SOCA), Perth, Australia.

Siena, A. (2010) "Engineering Law-Compliant Requirements. The Nòmos Framework", Ph.D. thesis, University of Trento, Italy.

Yu, E. (1997) "Towards Modelling and Reasoning Support for Early-Phase Requirements Engineering”, In: 3rd IEEE IEEE Intl. RE Conf., USA, pp. 226-235. 